\title{
SCREENING OF PROBIOTIC GOAT MILK TABLETS USING PLACKETT-BURMAN DESIGN*
}

\author{
He Chen, Jianhua Zhang, Guowei Shu \\ College of Life Science and Engineering, Shaanxi University of Science and Technology \\ 710021 Xi'an, China
}

\begin{abstract}
Background. Probiotics defined as additional microorganisms were added to goat milk powder, which not only improves the intestinal flora balance but also promotes human and animal health. The objectives of this study were to improve and guarantee high probiotics viable count and accordance with consumer's acceptance. Material and methods. The reading selected the number of colony between 30 and 300, then calculated the viable count per gram of goat milk tablet ( $\mathrm{cfu} / \mathrm{g}$ ). The items of sensory evaluation included: appearance, flavour, colour, texture and taste. The score test was composed of 5 trained assessors, scored combination of different formulations (full marks of 100 points) and recorded the results.

Results. Analysis of the results showed that sucrose, inulin and mannitol were selected as the main effective parameters on both viable count and sensory evaluation. Furthermore optimization of the formulation of probiotic goat milk tablets was to maximise the probiotics viable count to achieve $9.5 \cdot 10^{8} \mathrm{cfu} / \mathrm{g}$ and its scores of sensory evaluation to get 94 points.

Discussion. Future probiotics products will be combined with a variety of probiotics, which can display their respective advantages and characteristics. Thus the products will not only be in accordance with the requirements of human health and trend of social development, but also will quickly become a favorite among consumers.
\end{abstract}

Key words: probiotic goat milk tablets, viable count, sensory evaluation, Plackett-Burman design

\section{INTRODUCTION}

In recent years, goat milk and its products have become more popular than they were before. Goat milk has been reported to have higher digestibility and lower allergenic properties than cow milk, and also certain therapeutic values, which makes it attractive to consumers [Zhao et al. 2014, Haenlein 2004].The nutritional advantage of goat milk compared to cow milk has been attributed to the small size of fat globules. This is one of the proposed reasons for the easy digestion of goat milk [Kondyli et al. 2007, Khaowphan et al. 2010]. Therefore, goat milk is more suitable as health care food for infants, kids and elderly. Probiotics refer to the ability to promote balance of intestinal microflora, and play a beneficial effect on host as living microbial agent [Golden 1998, Lourens-Hattingh and Viljoen 2001]. Some authors also reported probiotics were defined as additional microorganism, by improving

\footnotetext{
* The project was partly supported by the science and technology plan project of Xi'an city [No. NC1317 (1)], the Science and Technology Research Development plan project of Shaanxi Province, China (No. 2014K01-17-07). 
the intestinal flora balance, it could promote human and animal health [Fuller 1989, Yuan et al. 2012].

What is more, there have appeared some reports on probiotic milk tablet [Natvaratat et al. 2007], probiotic ice cream from goat's milk [Silva et al. 2014], and probiotic yogurt [Lee et al. 2014]. There is growing scientific evidence that they had both the nutritional value of milk and special physiological functions of the probiotic. And specific strains of probiotic microorganisms confer health benefits on the host and are safe for human use [Aguirre-Ezkauriatza et al. 2010, Pham et al. 2008]. Especially, the advantages of milk tablet with high nutritive value are convenience, and suitable for the distribution to remote areas. Probiotic milk tablet can also overcome the shortcomings of liquid probiotic dairy storage difficult, short shelf-life and efficacy difficult to exert [Natvaratat et al. 2007]. However, there exist several problems that cause probiotics viable count decrease quickly and affect the viability of probiotic organisms during processing and storage [Tripathi and Giri 2014]. In order to further development of products, the optimization of the formula influences product qualities and acceptability [Earle and Earle 1999]. When optimizing a formulation, one common goal is to improve and guarantee probiotics viable count, and the other one is to maximize sensory acceptability, thus consumer tests must be conducted to determine which products are liked by the consumers [Yackinous et al. 1999, Natvaratat et al. 2007].

The present work was conducted with a single factor experiment, which experimental results are as follows: goat milk tablets of probiotic had optimal sucrose of $6 \%$, inulin of $1.0 \%$, xylitol of $4 \%$, acesulfame of $0.03 \%$, sodium erythorbate of $0.05 \%$, tea polyphenol of $0.015 \%$, microcrystalline cellulose of $0.3 \%$, and mannitol of $0.2 \%$, under these conditions, probiotics viable count of the tablets could be reached between $5.5 \cdot 10^{6} \mathrm{cfu} / \mathrm{g}$ and $1.0 \cdot 10^{7} \mathrm{cfu} / \mathrm{g}$, and the scores of sensory evaluation could be achieved between 65 points and 80 points. For further research, this work was designed to elucidate an effective approach that applied the Plackett-Burman design to achieve main effective parameters and find the optimum point. Thus the objectives of this study were to optimize the formulation of probiotic goat milk tablets and to improve and guarantee probiotics viable count of the tablets to achieve between $10^{7} \mathrm{cfu} / \mathrm{g}$ and $10^{9} \mathrm{cfu} / \mathrm{g}$, to increase its scores of sensory evaluation to get over 80 points. Thus this would determine its qualiative characteristics and target consumer acceptance.

\section{MATERIAL AND METHODS}

Chemicals and reagents. Goat milk powder was selected as the main component purchased from Shaanxi HongXing Company Ltd. (Shaanxi, China). The sucrose and acesulfame were selected mainly as a sweetener in order to improve the taste of sweetness. Inulin [Oliveira et al. 2011, Adebola et al. 2014], xylitol and mannitol were selected to promote the growth of probiotics. Sodium erythorbate and tea polyphenol were selected as an antioxidant, could effectively remove oxygen of milk tablets in order to avoid probiotics death, so as to improve the survival rate of probiotics. Microcrystalline cellulose was regarded as a kind of adhesive, which can effectively improve the degree of integration of products. All these above materials were purchased from Zhengzhou Datian Food Additive Company Ltd. (Henan, China).

Bacterial strains. Lactobacillus acidophilus was provided from College of Life Science and Engineering, Shaanxi University of Science and Technology. Colony counting culture medium was selected MRS agar medium purchased from Qingdao Hope Biol-Technology Co. Ltd. (Qingdao, China). They were sterilized under $121^{\circ} \mathrm{C}$ for $20 \mathrm{~min}$. Single punch tablet machine was purchased from Beijing Gylongli Sci \& Tech Co. Ltd. (Beijing, China).

Preparation of goat milk tablet. In the condition of sterile dry, spray-dried goat milk powder of Lactobacillus acidophilus were compressed on a single punch tablet machine [Khaowphan et al. 2010]. And the pray-dried goat milk powder of Lactobacillus acidophilus were composed of sucrose, inulin, xylitol, acesulfame, sodium erythorbate, tea polyphenol, microcrystalline cellulose, mannitol, which were regarded as excipients. The pressure should be controlled under $8 \pm 0.5 \mathrm{KN}$. The targeted tablet weight was set at $0.6 \pm 0.1 \mathrm{~g}$. Then the tablets were sampled to determine the viable count and conducted the sensory evaluation [Wu et al. 2012].

Measured the viable count of the probiotics product. Under the condition of sterile, 5 tablets taken (about $3 \mathrm{~g}$ ) were dissolved into anaerobic bottles 
Chen H., Zhang J., Shu G., 2014. Screening of probiotic goat milk tablets using Plackett-Burman design. Acta Sci. Pol., Technol. Aliment. 13(4), 351-358.

containing $27 \mathrm{ml}$ sterile physiological saline, and were mixed using vortex mixer, then $1 \mathrm{ml}$ to $9 \mathrm{ml}$ sterile physiological saline were added and the mixture was shaken after adding. Analogously, they were diluted to appropriate gradient, finally taking $1 \mathrm{ml}$ was evenly distributed in MRS solid agar. Each group was performed 3 parallel, and then placed in a constant temperature incubator at $37^{\circ} \mathrm{C}$ for $48 \mathrm{~h}$. The reading selected the number of colony between 30 and 300 , then calculated the viable count per gram of goat milk tablet (cfu/g).

Calculation formula. Five probiotic goat milk tablets were brushed to remove dust and then weighed (W). The viable count (W1) was determined per $\mathrm{mL}$ of bacteria suspension after five probiotic goat milk tablets smashed. The $\mathrm{W} 2$ was deputized for the volume of bacterial suspension. The viable count (Y1) of tablet was calculated from the viable count per gram of goat milk tablet, using the following equation:

$$
\mathrm{Y} 1(\mathrm{cfu} / \mathrm{g})=\mathrm{W} 1 \times \mathrm{W} 2 / \mathrm{W}
$$

Sensory evaluation. The score test was composed of 5 trained assessors, scored combination of different formulations (full marks of 100 points) and recorded the results. The items of sensory evaluation included: appearance, flavor, color, texture and taste. Then the Y2 value was used instead of average value of 5 results. Scoring rules were as shown in Table 3.

Plackett-Burman design. Twelve experiments representing the Plackett-Burman design have been

Table 1. Factor level coding table of Plackett-Burman

\begin{tabular}{ccccccccc}
\hline $\begin{array}{c}\text { Factor } \\
\text { level } \\
\%\end{array}$ & $\begin{array}{c}\mathrm{X} 1 \\
\text { (sucrose) }\end{array}$ & $\begin{array}{c}\mathrm{X} 3 \\
\text { (inulin) }\end{array}$ & $\begin{array}{c}\mathrm{X} 5 \\
\text { (xylitol) }\end{array}$ & $\begin{array}{c}\mathrm{X} 7 \\
\text { (acesulfame) }\end{array}$ & $\begin{array}{c}\mathrm{X} 8 \\
\text { (sodium } \\
\text { erythorbate) }\end{array}$ & $\begin{array}{c}\mathrm{X} 9 \\
\text { (tea polyphenol) }\end{array}$ & $\begin{array}{c}\mathrm{X} 10 \\
\text { (microcrystalline } \\
\text { cellulose) }\end{array}$ & $\begin{array}{c}\mathrm{X} 11 \\
\text { (mannitol) }\end{array}$ \\
\hline-1 & 5 & 0.7 & 3 & 0.02 & 0.04 & 0.014 & 0.2 & 0.1 \\
1 & 7 & 1.3 & 5 & 0.04 & 0.06 & 0.018 & 0.4 & 0.3 \\
\hline
\end{tabular}

Table 2. Experimental design and results of Plackett-Burman

\begin{tabular}{rrrrrrrrrrrrrr}
\hline RUN & X1 & X2 & X3 & X4 & X5 & X6 & X7 & X8 & X9 & X10 & X11 & $\begin{array}{c}\text { Y1 } \\
\times 10^{7} / \mathrm{cfu} / \mathrm{g}\end{array}$ & $\begin{array}{c}\text { Y2 } \\
\text { points }\end{array}$ \\
\hline 1 & 1 & -1 & 1 & -1 & -1 & -1 & 1 & 1 & 1 & -1 & 1 & 80 & 88 \\
2 & 1 & 1 & -1 & 1 & -1 & -1 & -1 & 1 & 1 & 1 & -1 & 20 & 85 \\
3 & -1 & 1 & 1 & -1 & 1 & -1 & -1 & -1 & 1 & 1 & 1 & 90 & 87 \\
4 & 1 & -1 & 1 & 1 & -1 & 1 & -1 & -1 & -1 & 1 & 1 & 95 & 94 \\
5 & 1 & 1 & -1 & 1 & 1 & -1 & 1 & -1 & -1 & -1 & 1 & 20 & 84 \\
6 & 1 & 1 & 1 & -1 & 1 & 1 & -1 & 1 & -1 & -1 & -1 & 0.3 & 82 \\
7 & -1 & 1 & 1 & 1 & -1 & 1 & 1 & -1 & 1 & -1 & -1 & 0.2 & 83 \\
8 & -1 & -1 & 1 & 1 & 1 & -1 & 1 & 1 & -1 & 1 & -1 & 0.1 & 80 \\
9 & -1 & -1 & -1 & 1 & 1 & 1 & -1 & 1 & 1 & -1 & 1 & 5.5 & 78 \\
10 & 1 & -1 & -1 & -1 & 1 & 1 & 1 & -1 & 1 & 1 & -1 & 4.5 & 75 \\
11 & -1 & 1 & -1 & -1 & -1 & 1 & 1 & 1 & -1 & 1 & 1 & 1.1 & 80 \\
12 & -1 & -1 & -1 & -1 & -1 & -1 & -1 & -1 & -1 & -1 & -1 & 1.0 & 80 \\
\hline
\end{tabular}


Table 3. Sensory score of milk tablets

\begin{tabular}{|c|c|c|c|c|c|}
\hline Project & $\begin{array}{l}\text { Surface } \\
\text { (15 points) }\end{array}$ & $\begin{array}{l}\text { Colour } \\
\text { (15 points) }\end{array}$ & $\begin{array}{c}\text { Taste } \\
\text { (25 points) }\end{array}$ & $\begin{array}{l}\text { Flavour } \\
\text { (25 points) }\end{array}$ & $\begin{array}{l}\text { Texture } \\
\text { (20 points) }\end{array}$ \\
\hline Good & $\begin{array}{l}12 \sim 15 \\
\text { complete shape, } \\
\text { uniform thickness, } \\
\text { neat edge, } \\
\text { smooth (shiny } \\
\text { and even) }\end{array}$ & $\begin{array}{l}12 \sim 15 \\
\text { creamy or canary } \\
\text { yellow, } \\
\text { there are no spots, } \\
\text { colour is uniform }\end{array}$ & $\begin{array}{l}20 \sim 25 \\
\text { no astringent flavour } \\
\text { or rough sense (taste } \\
\text { smooth), } \\
\text { chew easily } \\
\text { (non-stick teeth) }\end{array}$ & $\begin{array}{l}20 \sim 25 \\
\text { goat milk flavour } \\
\text { is slightly, } \\
\text { non eggy } \\
\text { and fishy smell } \\
\text { (smell pleasantly) }\end{array}$ & $\begin{array}{l}15 \sim 20 \\
\text { structure of the endo- } \\
\text { plasmic reticulum is } \\
\text { fine and uniform, } \\
\text { cross section tis- } \\
\text { sue structure looks } \\
\text { closely }\end{array}$ \\
\hline Common & $\begin{array}{l}9 \sim 11 \\
\text { basic integrity, } \\
\text { exsit a small amount } \\
\text { of damage, } \\
\text { basic smooth } \\
\text { (no uneven) }\end{array}$ & $\begin{array}{l}9 \sim 11 \\
\text { canary yellow or } \\
\text { white, } \\
\text { exsit a small number } \\
\text { of spots, } \\
\text { colour is uniform } \\
\text { basically }\end{array}$ & $\begin{array}{l}15 \sim 19 \\
\text { a little astringent fla- } \\
\text { vour (taste essentially } \\
\text { smooth, no rough } \\
\text { sense), } \\
\text { chew easily (non } \\
\text { stick teeth) }\end{array}$ & $\begin{array}{l}15 \sim 19 \\
\text { goat milk flavour } \\
\text { is slightly, } \\
\text { eggy and fishy smell } \\
\text { are slightly (accept- } \\
\text { able smell) }\end{array}$ & $\begin{array}{l}11 \sim 14 \\
\text { structure of the en- } \\
\text { doplasmic reticulum } \\
\text { is basically uniform, } \\
\text { cross section tissue } \\
\text { structure looks basic } \\
\text { density }\end{array}$ \\
\hline Bad & $\begin{array}{l}<9 \\
\text { incomplete shape, } \\
\text { seriously broken, } \\
\text { uneven }\end{array}$ & $\begin{array}{l}<9 \\
\text { dark yellow, } \\
\text { large number of } \\
\text { spots, } \\
\text { colour is uneven }\end{array}$ & $\begin{array}{l}<15 \\
\text { strongly astringent } \\
\text { flavour (rough taste, } \\
\text { hard to swallow), } \\
\text { chew difficultly } \\
\text { (sticky teeth) }\end{array}$ & $\begin{array}{l}<15 \\
\text { goat milk flavour is } \\
\text { too strong or not, } \\
\text { eggy and fishy smell } \\
\text { are strong (smell } \\
\text { pungently) }\end{array}$ & $\begin{array}{l}<11 \\
\text { loose endoplasmic } \\
\text { structure, cross sec- } \\
\text { tion is loose or even } \\
\text { powder appears }\end{array}$ \\
\hline
\end{tabular}

designed to conduct the randomization step as in Table 1 and to a correctly enable the regression analysis. Each experiment contained only either the +1 or -1 value of each variables. However, it contained an entirely different variable represented by +1 or -1 . None of the twelve experiments was similar to the other [Amara et al. 2013]. Using Plackett-Burman design was to screen out the main factors of the effect on 12 factors on the viable count and sensory evaluation.

\section{RESULTS AND DISCUSSION}

\section{Screening of the main factors using Plackett-Burman design}

Although the influence of various factors on sugar, alcohol and antioxidants had a general understanding through the single factor experiment, the relationship between primary and secondary could not be determined. If sugar, alcohol and antioxidants were certainly conducted effectively and applied to industrial production, and manufacturers might greatly be encouraged to diversify. Therefore, Plackett-Burman (PB) designs were screening designs that each factor at two levels was carried on the analysis. Through comparing the differences between each factor at two levels with the overall in order to determine the significant factor, several main influencing factors could be screened out and avoided to waste test resources in the later period of the optimization test due to the factor number too much or partial factor not significant enough.

The design used was the Plackett-Burman one that comprised 11 factors spanning over 12 runs with each factor fixed at two levels (namely a low and high levels). And the effect analysis of single factor was carried out on to find the larger influence factors. The factor level coding table and the experimental results of Plackett-Burman were shown in Table 1 and Table 2. Table 3 showed the sensory score of milk tablets. Table 2 showed that the X2, X4 and X6 were virtual items, the Y1 value was the viable count, the Y2 value was the scores of sensory evaluation.

As shown in Table 1, each of eight factors was set to two gradients, respectively. And there existed more reasonable range between each factor gradient. Analysis of Table 2 experimental data 


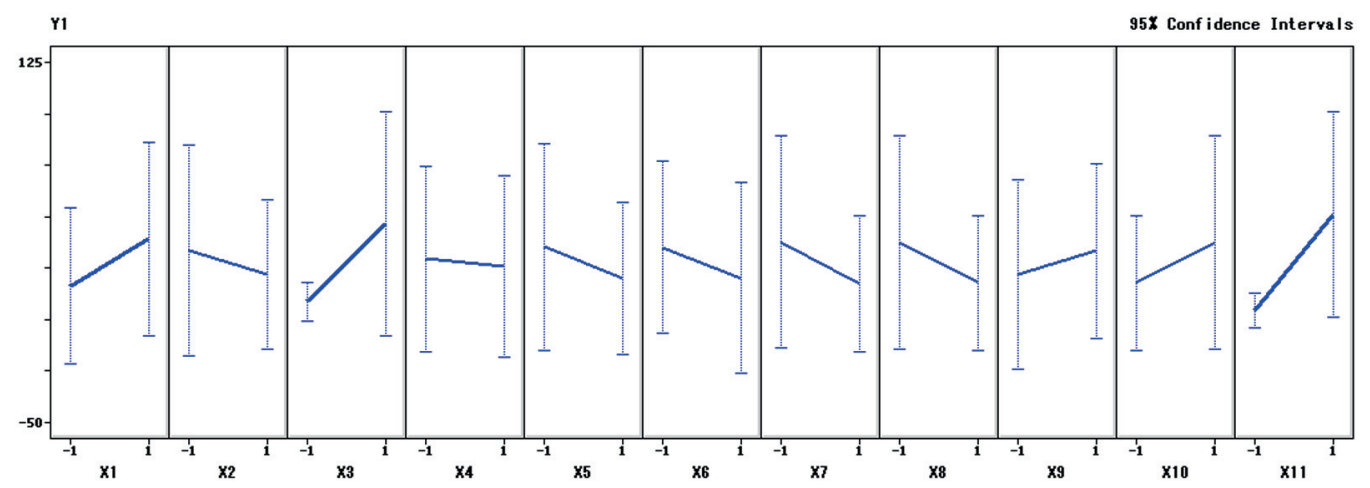

Fig. 1. $95 \% \mathrm{CI}$ interval graph of factors

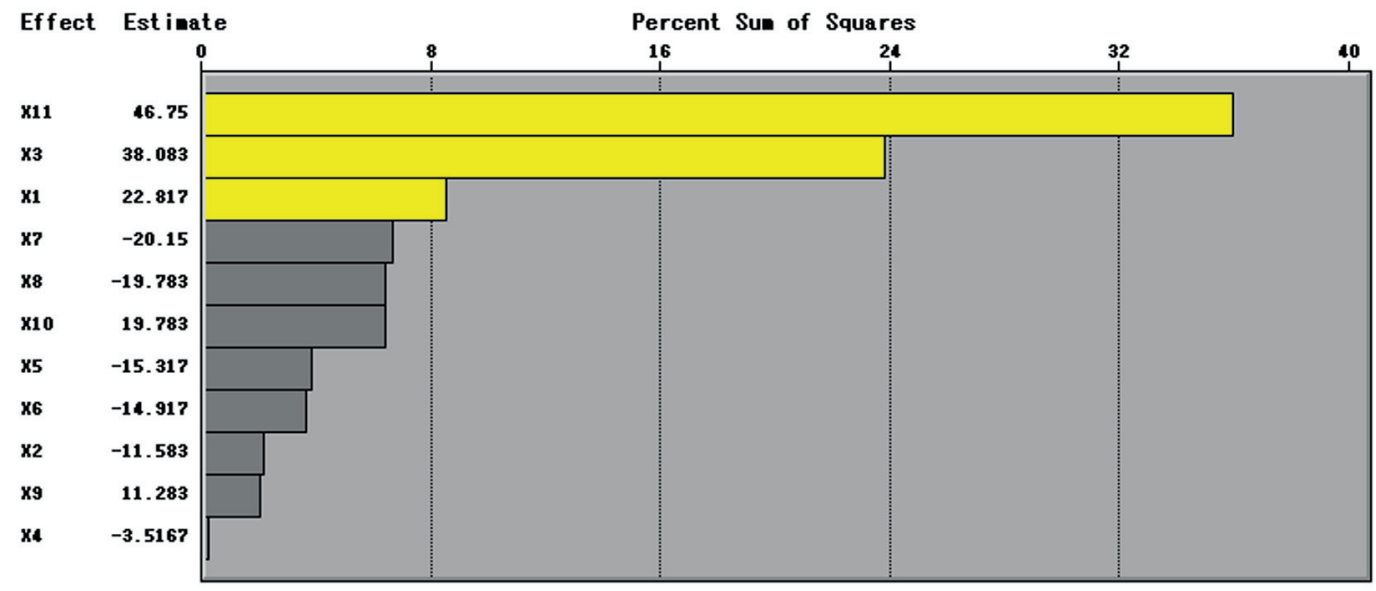

Fig. 2. Screening results of the main factors of Plackett-Burman

was also done to determine and maximise the probiotics viable count (Y1) to achieve $9.5 \cdot 10^{8} \mathrm{cfu} / \mathrm{g}$ and its scores of sensory evaluation (Y2) to get 94 points, which displayed that the surface of the tablets looked smooth or shiny, shape was complete, thickness was uniform, edge was neat, colour was creamy and uniform, taste was not rough, slight goat milk flavour and easy to chew, texture was basically uniform and close.

As illustrated in Figure 1 the data for the components in milk samples were analysed using t-test with the $95 \%$ confidence interval $(p<0.05)$. Effects of various factors on the viable count can be displayed, where X1, X3, X9, X10 and X11 were positive, but X2,
$\mathrm{X} 5, \mathrm{X} 6, \mathrm{X} 7$ and $\mathrm{X} 8$ were negative, and the effect of X4 was not obvious. As shown in Figure 2 the relationship between primary and secondary influence of the effect on the viable count can be found as follows: X11 > X3 $>\mathrm{X} 1$. The proportion of X11 reached more than $32 \%$. This showed that the effect of mannitol (X11) on the growth and reproduction of Lactobacillus acidophilus was more obvious than of others. And although the proportion of inulin (X3) was not very high, it could be seen that inulin had a certain role in promoting the growth of probiotics [Oliveira et al. 2011, Adebola et al. 2014]. And the X1 was more obvious and its proportion reached more than $8 \%$. Except items of $\mathrm{X} 7, \mathrm{X} 8$ and $\mathrm{X} 10$, the ratio of $\mathrm{X} 2, \mathrm{X} 4, \mathrm{X} 5, \mathrm{X} 6$ and $\mathrm{X} 9$ 


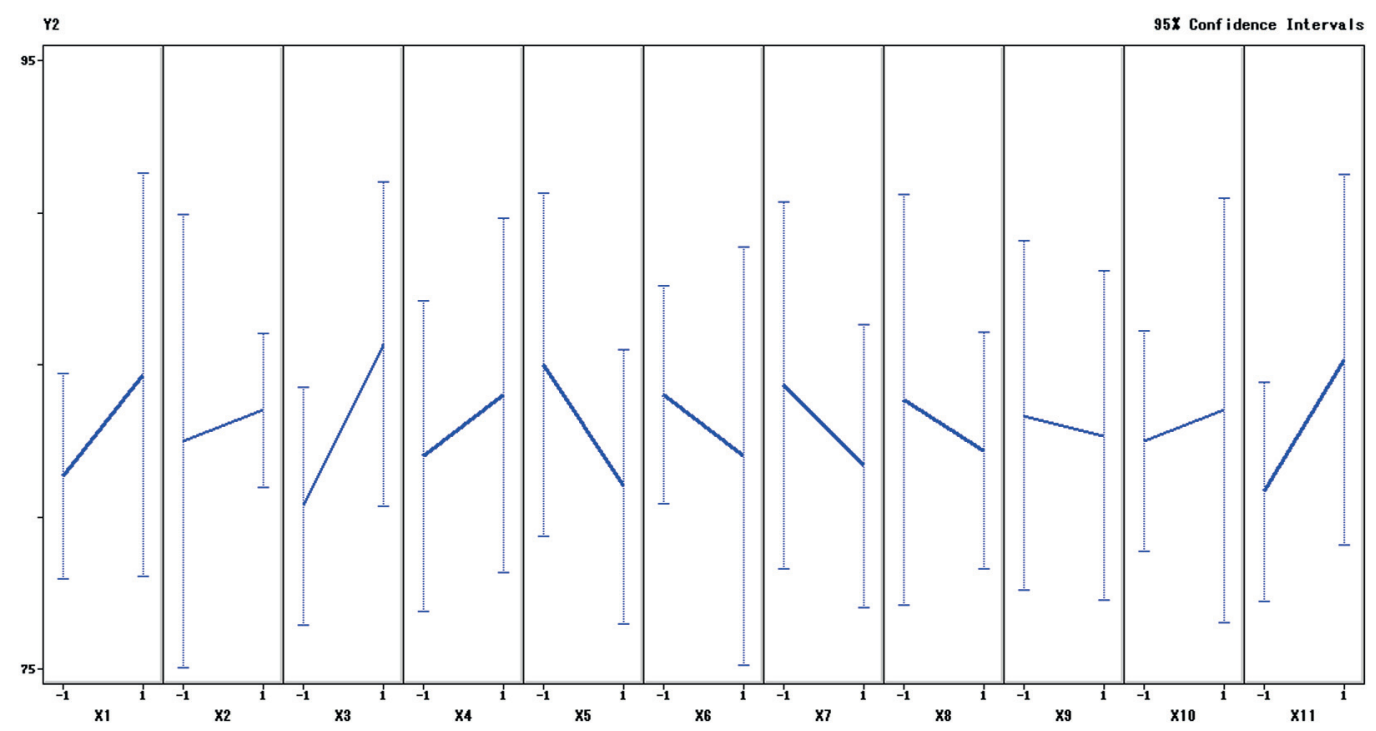

Fig. 3. $95 \% \mathrm{CI}$ interval graph of factors

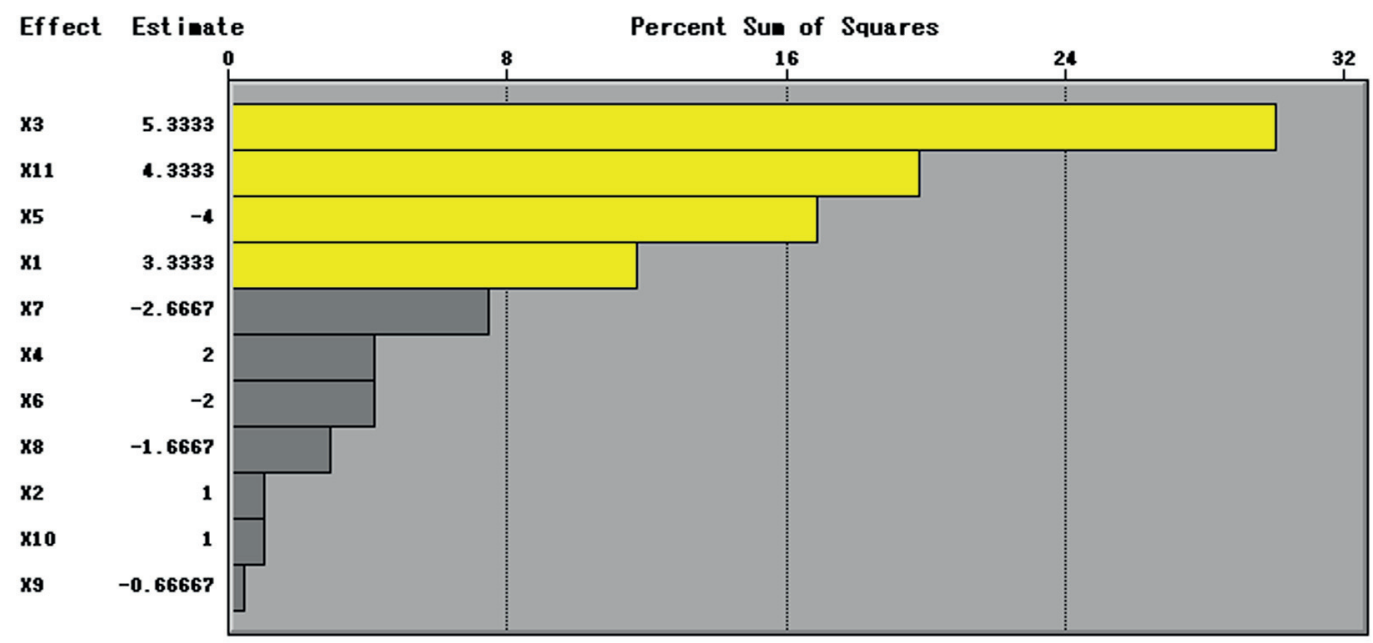

Fig. 4. Screening results of the main factors of Plackett-Burman

were less than $5 \%$ and their impacts were very small. Analysis of the results showed that the X1, X3 and $\mathrm{X} 11$ were the main effective parameters on the viable count.

As illustrated in Figure 3 the data for the components in milk samples were also analysed using t-test with the 95\% confidence interval $(p<0.05)$.
Effects of various factors on sensory evaluation can be displayed, where X1, X2, X3, X4, X10 and X11 were positive effect, and $\mathrm{X} 5, \mathrm{X} 6, \mathrm{X} 7, \mathrm{X} 8$ and $\mathrm{X} 9$ were negative effect, but the effect of X9 and X10 was not significantly obvious. As shown in Figure 4 the relationship between primary and secondary of the influence of the effect on sensory evaluation can be 
found as follows: X3 $>$ X11 $>$ X5 $>$ X1. The effect of $\mathrm{X} 3$ was the most obvious and its proportion reached more than $32 \%$. And the X1, X5, X11 were the more obvious and its proportion reached between 10\% and $20 \%$. Except the items of X4, X6, X7 and X8, the ratio of $\mathrm{X} 2, \mathrm{X} 9$ and $\mathrm{X} 10$ were less than $5 \%$ and their impacts were very small. Analysis of the results showed that the X1, X3, X5 and X11 were the main effective parameters on sensory evaluation.

To summarize the above analysis, from Figure 2 it can be seen that X1, X3 and X11 were the main effective parameters on the viable count. And from Figure 4 it can be seen that X1, X3, X5 and X11 were the main effective parameters in relation to sensory evaluation. But from Figure 1 and Figure 3 it can be known that X5 were negative and the effect was not significantly obvious. It meant that with the increase of $\mathrm{X} 5$ content, although the impact on $\mathrm{Y} 1$ is not too strong, decreasing trend would be gradually shown. So the impact of this factor would be not considered in this experiment. Therefore X1, X3 and X11 were selected as the main effective parameters on both viable count and sensory evaluation.

\section{CONCLUSIONS}

The Plackett-Burman designs were advantageously applied to study the main effective parameters on both viable count and sensory evaluation. The influence of each factor on both viable count and sensory evaluation had certain effect. However, the final conclusion was that the sucrose, inulin and mannitol were selected as the main factors.

\section{REFERENCES}

Adebola O.O., Corcoran O., Morgan W.A., 2014. Synbiotics: the impact of potential prebiotics inulin, lactulose and lactobionic acid on the survival and growth of lactobacilli probiotics. J. Funct. Foods 10, 75-84.

Aguirre-Ezkauriatza E.J., Aguilar-Yáñez J.M., Ramírez-Medrano A., Alvarez M.M., 2010. Production of probiotic biomass (Lactobacillus casei) in goat milk whey: Comparison of batch, continuous and fed-batch cultures. Biores. Techn. 101, 2837-2844.

Amara A.A., Salem-Bekhit Mounir M., Alanazi F.K., 2013. Plackett-Burman randomization method for Bacterial
Ghosts preparation form E. coli JM109. Saudi Pharm. J. 6 (2), 1-7.

Earle M., Earle R., 1999. Creating new foods: The product developer's guide. Chandos Publ., Oxford.

Fuller R., 1989. Probiotics in man and animals. J. Appl. Bact. 66, 365-378.

Golden B.R., 1998. Health benefits of probiotic. Brit. J. Nutr. 80 (12), 203-207.

Haenlein G.F.W., 2004. Goat milk in human nutrition. Small Rum. Res. 51, 155-163.

Khaowphan N., Mitrevej A., Ruangwises N., 2010. Nutritional values and stability of goat milk tablets. Mahidol Univ. J. Pharm. Sci. 37 (3-4), 12-20.

Kondyli E., Katsiari M.C., Voutsinas L.P., 2007. Variations of vitamin and mineral contents in raw goat milk of the indigenous Greek breed during lactation. Food Chem. 100, 226-230.

Lee N.-K., Kim S.-Y., Han K.J., Eom S.J., Paik H.-D., 2014. Probiotic potential of Lactobacillus strains with anti-allergic effects from kimchi for yogurt starters. LWT Food Sci. Techn. 58 (1), 130-134.

Lourens-Hattingh A., Viljoen B.C., 2001. Yogurt as probiotic carrier food. Int. Dairy J. 11, 1-17.

Natvaratat M., Chompreeda P., Haruthaithanasan V., Rimkeeree V., 2007. Optimization of supplementary protein milk tablet formulation for rural school children under her royal highness princess Maha Chakri Sirindhorn's Project. Kasetsart J. (Nat. Sci.) 41, 733-739.

Oliveira R., Perego P., Oliveira M., Converti A., 2011. Effect of inulin as prebiotic and synbiotic interactions between probiotics to improve fermented milk firmness. J. Food Eng. 107, 36-40.

Pham M., Lemberg D.A., Day A.S., 2008. Probiotics: sorting the evidence from the myths. Medical J. Austr. 188 (5), 304-308.

Silva P., Bezerra M.F., Santos K.M., Correia R.T.P., 2014. Potentially probiotic ice cream from goat's milk: Characterization and cell viability during processing, storage and simulated gastrointestinal conditions. LWT - Food Sci. Techn. 3, 55-60.

Tripathi M.K., Giri S.K., 2014. Probiotic functional foods: Survival of probiotics during processing and storage. J. Funct. Foods 9, 225-241.

Wu J., Yang Ch., Rong Y., Wang Z., 2012. Preparation and nutritional characterization of perilla chewable tablet. Proc. Eng. 37, 202-207.

Yackinous C., Wee C., Guinard J.X., 1999. Internal preference mapping of hedonic ratings for Ranch salad dressings varying in fat and garlic flavour. Food Qual. Prefer. 10, 401-409. 
Chen H., Zhang J., Shu G., 2014. Screening of probiotic goat milk tablets using Plackett-Burman design. Acta Sci. Pol., Technol. Aliment. 13(4), 351-358.

Yuan L., Ma J., Ding M., Wang S., Wu X., Li Y., Ma K., Zhou X., Li F., 2012. Preparation of estriol-molecularly imprinted silica nanoparticles for determining oestrogens in milk tablets. Food Chem. 131, 1063-1068.
Zhao L., Zhang S., Uluko H., Liu L., Lu J., Xue H., Kong F., Lv J., 2014. Effect of ultrasound pretreatment on rennet-induced coagulation properties of goat's milk. Food Chem. 165, 167-174.

Accepted for print - Zaakceptowano do druku: 28.07.2014

Received - Przyjęto: 9.06.2014

For citation - Do cytowania

Chen H., Zhang J., Shu G., 2014. Screening of probiotic goat milk tablets using Plackett-Burman design. Acta Sci. Pol., Technol. Aliment. 13(4), 351-358 